\title{
Lignin as immobilization matrix for HIV p17 peptide used in immunosensing
}

\author{
Bianca M. Cerrutti ${ }^{\text {a,* }}$, Marli L. Moraes ${ }^{b}$, Sandra H. Pulcinelli ${ }^{\text {a }}$, Celso V. Santilli ${ }^{\text {a }}$ \\ a Instituto de Química, Universidade Estadual Paulista, Araraquara, SP, Brazil \\ ${ }^{\mathrm{b}}$ Instituto de Ciência e Tecnologia, Universidade Federal de São Paulo, São José dos Campos, SP, Brazil
}

\section{A R T I C L E I N F O}

\section{Article history:}

Received 26 January 2015

Received in revised form

14 April 2015

Accepted 17 April 2015

Available online 20 April 2015

Keywords:

Layer-by-layer films

Immunosensors

HIV

Lignin

Peptides

Impedance spectroscopy

\begin{abstract}
A B S T R A C T
Immunosensors based on electrical impedance spectroscopy (EIS) are increasingly being used as a fast and potentially low cost method for clinical diagnostics. In this work we fabricated immunosensors by depositing layer-by-layer (LbL) films made with an antigenic peptide (p17-1) sequence $\left(\mathrm{H}_{2} \mathrm{~N}\right.$-LSGGELDRWEKIRLRPGG-OH) and lignin on interdigitated gold electrodes, which could detect antip17 (HIV, human immune deficiency virus) antibodies (Ab) in phosphate buffered solutions (PBS). The molecular recognition interaction between the peptide (p17-1) and the specific Ab (anti-p17) yielded substantial changes in morphology of the with LbL films, with increased roughness according to atomic force microscopy data. This interaction is behind the high sensitivity of the immunosensor. Indeed, from the EIS results, we noted that the capacitance increased significantly with the specific Ab concentration, before getting close to saturation of available peptide sites at high concentrations. Concentrations of specific antibodies as low as $0.1 \mathrm{ng} / \mathrm{mL}$ could be detected and the immunosensors had their activity preserved for two months at least. The selectivity of the immunosensor was confirmed with two types of control experiments. First, no changes in impedance were observed when the lignin/peptide LbL immunosensor was immersed into a PBS solution containing the non-specific Ab (anti-HCV for Hepatitis C) antibodies. Furthermore, for sensing units made LbL films of lignin only, the electrical response was not affected by adding specific antibodies into the PBS buffer. The successful immunosensing for HIV with antigenic peptides in a lignin matrix is also relevant for valorization of lignin, which is an important biomass component in the sugar and ethanol industry, and brings the prospect for all-organic, biocompatible sensors if implantation is ever required.
\end{abstract}

(c) 2015 Elsevier B.V. All rights reserved.

\section{Introduction}

Immunosensors have become essential devices in clinical diagnosis owing to their high sensitivity, selectivity and stability, as they are based on molecular recognition and lock-and-key mechanisms (Hirotsu et al., 2005; Sacanna et al., 2010). Various are the methods based on immunoessays, but perhaps the most widespread is the enzyme-linked immunosorbent assay (ELISA) (Zheng et al., 2012; Gan et al., 2013; Bhimji et al., 2013; Makaraviciute and Ramanaviciene, 2013). Generally these methods are suitable for use in clinical analysis laboratories, but there is growing interest in immunosensors that can be used in the socalled point-of-care places. In addition to being useful for diagnosing a number of diseases, immunosensors may be applied to monitor allergenic substances in food safety, and detect pollutants,

\footnotetext{
* Corresponding author.

E-mail address: bicerr@gmail.com (B.M. Cerrutti).
}

chemical and biological warfare agents. Such immunosensors can exploit either electrochemical (Dhand et al., 2011) or electrical impedance spectroscopy (EIS) (Mishra et al., 2012; Lu et al., 2012; Liu et al., 2013) principles of detection, and are normally made with nanostructured films. Suitable biomolecules capable of molecular recognition are then required for immobilization in a solid matrix. Main requirements for an immunosensor are: (i) An element capable of molecular recognition; (ii) Immobilization of the element preserving its activity; (iii) Suitable immobilization matrix; (iv) Method of assembling the components.

In this study we use the layer-by-layer (LbL) method (Ferreira et al., 2013; Gasparotto et al., 2013; Aoki et al., 2013), based on electrostatic attraction of oppositely charged layers, to fabricate immunosensors. The LbL technique is suitable for biomaterial processing due to the mild conditions for film fabrication, in addition to the simple and low cost instrumentation required. Furthermore, adsorption may be driven by H-bonding as well, and most importantly, some entrapped water is retained which helps 
preserve the structure of the biomolecule. With regard to the choice of components, suitable matrices for biosensors (including immunosensors) in LbL films have been chitosan (Sombatsri et al., 2012; Luo et al., 2013), liposomes (Karlsson et al., 2002; Moraes et al., 2010), dendrimers (Giannetto et al., 2011; Vieira et al., 2012) and silk fibroin (Yin et al., 2009; Moraes et al., 2013). Here we propose to use lignin for immobilizing an antigenic peptide in LbL films; actually the first time it is used as a matrix for this purpose to the best of our knowledge.

Lignin imparts mechanical resistance to plants and protects them against biodegradation and penetration of pathogens. It is present in the plant cell walls and gives the brown color to paper in the paper industry. Since it has no repeating unit, lignin is a biomacromolecule but not a polymer, being based on phenyl propanic units such as hydroxy phenyl $(H)$, guaiacyl $(G)$, and siringyl (S), linked mainly by $\beta-0-4$ bonds (Cerrutti et al., 2012). There are two main reasons for choosing lignin as matrix for biosensors: (a) it is biocompatible, which is important if immunosensors should ever be implanted; and (b) the valorization of the lignin is strategic for countries that produce a lot of biomass. In Brazil, in particular, large amounts of sugar cane bagasse are generated in the alcohol and sugar cane industry, and lignin is mostly burnt to generate energy (Oliverio and Hilst, 2004).

Most immunosensors employ either antigenic peptides or antibodies. Using a peptide is advantageous because of its higher stability, low cost and easier handling, with its much smaller size. Here we used an antigenic peptide ( $\mathrm{p}-17$ ) that corresponds to the specific region of an antigen where molecular recognition of the specific Ab occurs. We employed an antigenic peptide that plays the role of an antigen, in order to recognize the Ab specific for HIV, an Ab of the human immune deficiency virus associated with AIDS (Acquired Immune Deficiency Syndrome). Here we shall show that the lignin matrix is able to maintain the secondary $\alpha$-helix structure of the peptide essential for molecular recognition. This feature represents a real advantage with respect to known LbL HIV immunosensors in which the peptide $\mathrm{p}-17$ needs to be protected into liposomes (Moraes et al., 2013).

\section{Experimental details}

\subsection{Materials and solutions}

Lignin was extracted from sugar cane bagasse using an organosolv process, developed by the Brazilian company Dedini (Oliverio and Hilst, 2004). The lignin solution was prepared with $0.05 \mathrm{~g}$ of lignin in $10 \mathrm{~mL}$ methanol, at room temperature under stirring for $15 \mathrm{~h}$, which was then filtered with a Millipore $33 \mathrm{~mm}$ filter and had $90 \mathrm{~mL}$ of Milli-Q water added. Since it is rich in functional groups, with hydroxyls being the most reactive ones, lignin is capable of H-bonding as indicated in Fig. 1.

The peptide p17- 1 sequence $\mathrm{H}_{2} \mathrm{~N}$-LSGGELDRWEKIRLRPGG-OH was synthesized and purified by AminoTech P\&D. Anti-p17 (specific $\mathrm{Ab}$ ) and anti-HCV antibodies (non-specific $\mathrm{Ab}$ ) were supplied by Santa Cruz Biotechnology Inc. All materials were used as received. The peptide aqueous solution was prepared with $0.5 \mathrm{mg}$ in $1 \mathrm{~mL}$ PBS (phosphate buffered saline solution). The stock solution for the antibodies had a concentration of $0.1 \mu \mathrm{g} / \mathrm{mL}$ in PBS. Different concentrations were prepared from the stock solution: $0.01 \mu \mathrm{g} / \mathrm{mL}, 0.001 \mu \mathrm{g} / \mathrm{mL}, 0.0001 \mu \mathrm{g} / \mathrm{mL}$.

\subsection{Layer-by-layer films}

The lignin/peptide layer-by-layer (LbL) films were produced with alternating substrate immersions into solutions of lignin for $15 \mathrm{~min}$ and of peptide during $10 \mathrm{~min}$, and in each immersion step the film was washed with Milli-Q water and dried with a nitrogen flow. For the films containing only lignin we used the same procedure without immersion into the peptide solution. Multilayer growth for lignin/peptide and lignin films was monitored with UV-vis spectroscopy using a Cary 60 for each bilayer, or layer, deposited. The substrates for absorption measurements were made of quartz slides (10 $\mathrm{mm} \times 5 \mathrm{~mm} \times 2 \mathrm{~mm}$ ), previously cleaned in $\mathrm{HCl} / \mathrm{H}_{2} \mathrm{O}_{2} / \mathrm{H}_{2} \mathrm{O}(1: 1: 6(\mathrm{v} / \mathrm{v}))$ and $\mathrm{NH}_{4} \mathrm{OH} / \mathrm{H}_{2} \mathrm{O}_{2} / \mathrm{H}_{2} \mathrm{O}(1: 1: 5(\mathrm{v} / \mathrm{v}))$ hydrophilization solutions, both for $10 \mathrm{~min}$ at $80^{\circ} \mathrm{C}$. For impedance spectroscopy, interdigitated gold electrodes were used with 50 pairs of $10 \mu \mathrm{m}$ wide fingers, separated by $10 \mu \mathrm{m}$ from each other, and area of $10 \mathrm{~mm}^{2}$.

\subsection{Detection measurements from electrical impedance spectro- scopy (EIS)}

In the sensing experiments, a Solartron model SI 1260 was used for measuring electrical impedance in the frequency range from $1 \mathrm{~Hz}$ to $1 \mathrm{MHz}$ with 10 points/decade, using an a.c. amplitude of $50 \mathrm{mV}$. The sensing units were made with 2-bilayer LbL films deposited onto interdigitated gold electrodes. This 2-bilayer film was chosen in optimization experiments with films varying from 1 to 5 bilayers. We did not try thicker films because biosensors made with LbL films are most sensitive when less than 5 or 6 bilayers are deposited since the electrical conductance may drop in thick films (Moraes et al., 2010). On the other hand, coverage of the electrodes may be insufficient for just onebilayer film, and in the present case the 2-bilayer LbL film was shown to provide the best tradeoff between thickness and amount of active biomolecules. The immunoassay experiments were performed by adding $50 \mu \mathrm{L}$ of specific antibodies in PBS solution at various concentrations $\quad\left(0.0001 \mu \mathrm{gmL}^{-1}, \quad 0.001 \mu \mathrm{gmL}^{-1}, \quad 0.01 \mu \mathrm{gmL}^{-1}\right.$, $0.1 \mu \mathrm{gmL}^{-1}$ ) on the sensing unit. In control experiments to test selectivity, a PBS solution and another PBS solution containing a nonspecific $\mathrm{Ab}\left(0.1\right.$ and $\left.0.001 \mu \mathrm{gmL}^{-1}\right)$ were dropped onto the sensing unit. All the measurements were repeated four times for each sensing unit. Fig. 2 shows the scheme of the sensor diagram and detection of specific Ab. Detection based on EIS is similar in many respects to the electrochemical methods, but has the advantage of not requiring a reference electrode (Moraes et al., 2010).

\subsection{Atomic force spectroscopy (AFM)}

The morphology of LbL films deposited on a quartz substrate $(10 \mathrm{~mm} \times 5 \mathrm{~mm} \times 2 \mathrm{~mm})$ was studied with AFM using a 5500AC

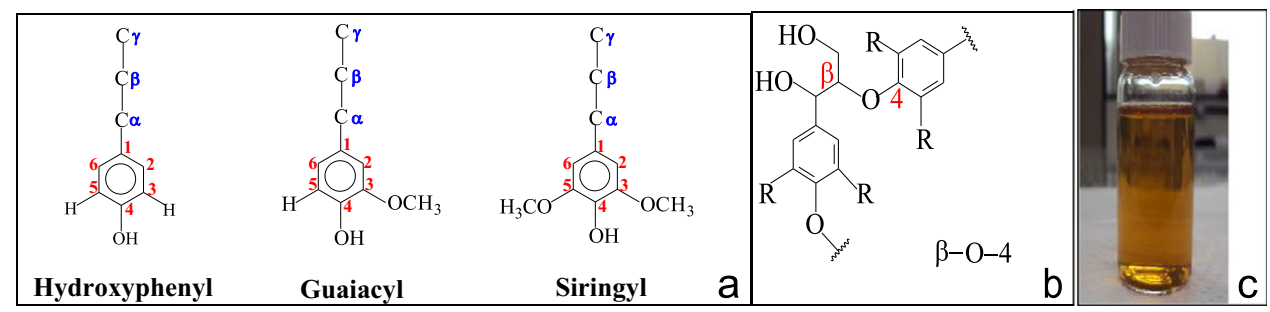

Fig. 1. (a) Structural units of lignin; (b) linkage between lignin units; and (c) lignin in methanol solution. 


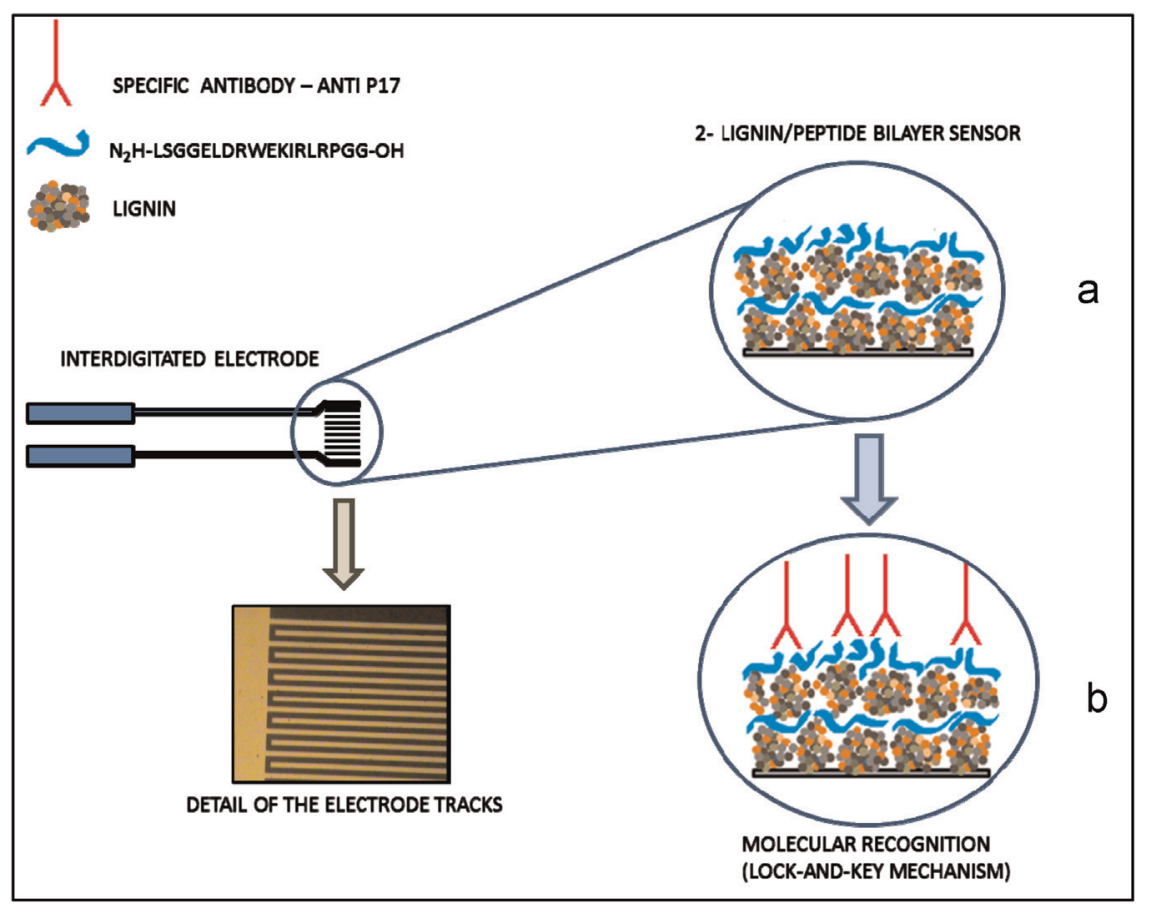

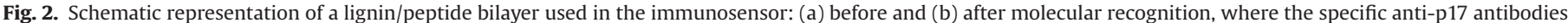
adsorb onto the immunosensor. The interdigitated gold electrode had 50 pairs of $10 \mu \mathrm{m}$ wide fingers, separated by $10 \mu \mathrm{m}$ from each other and an area of 10 mm ${ }^{2}$.

Mode III microscope (Agilent Technology). Images with $512 \times 512$ pixels were obtained under ambient conditions in the tapping mode using standard Si cantilevers. The roughness of the film surface is expressed in terms of the root-mean-square (RMS) value.

\subsection{Statistical analyses with multidimensional projection-IDMAP}

The impedance data were treated with a multidimensional projection technique, referred to as Interactive Data Mapping
(IDMAP) (Moraes et al., 2010; Volpati et al., 2011). This technique has been shown suitable for visualization of sensing data as reported in (Moraes et al., 2010; Siqueira et al., 2010; Paulovich et al., 2011; Oliveira et al., 2012). With IDMAP an initial mapping of the data instances is performed, which is then improved by using the Force Scheme strategy (Moraes et al., 2010; Minghim et al., 2006). With the latter, placement is improved by mimicking a massspring system with attraction and repulsion forces, in a similar fashion to well-known graph-layout approaches. Such procedures
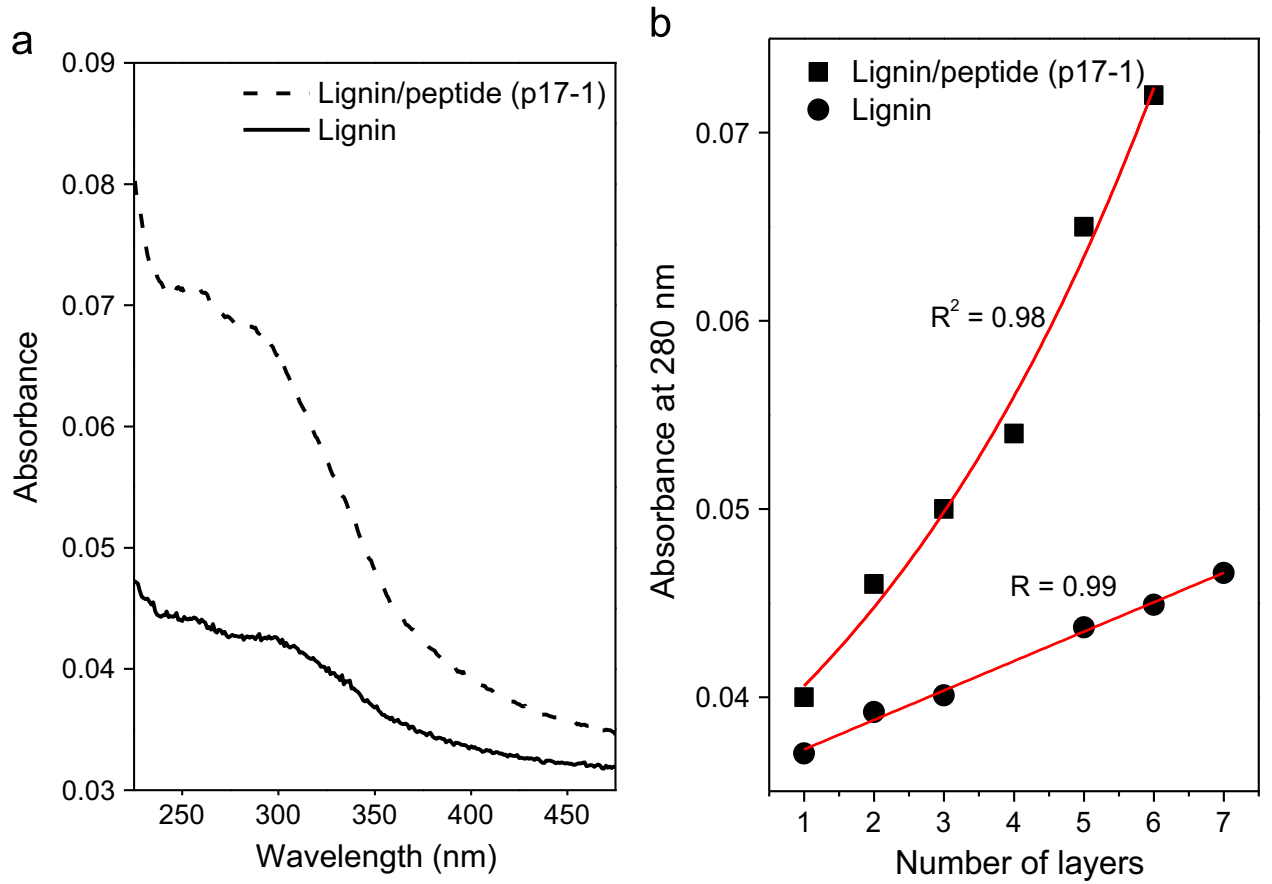

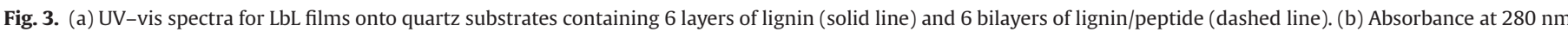

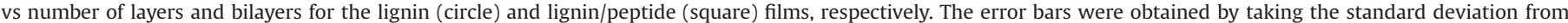
three measurements. 
a

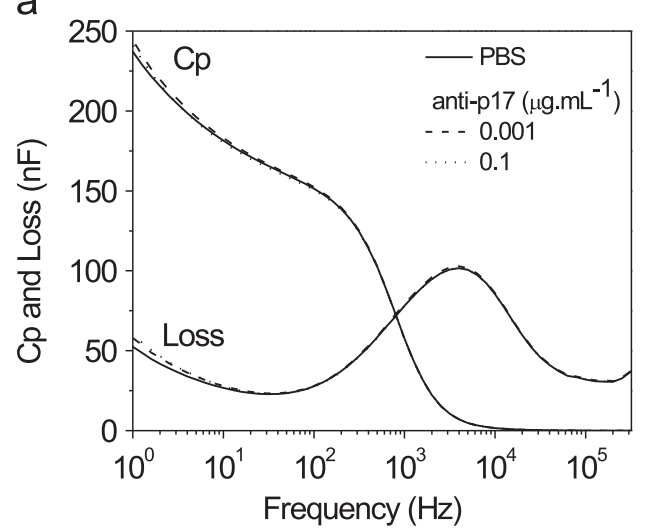

b

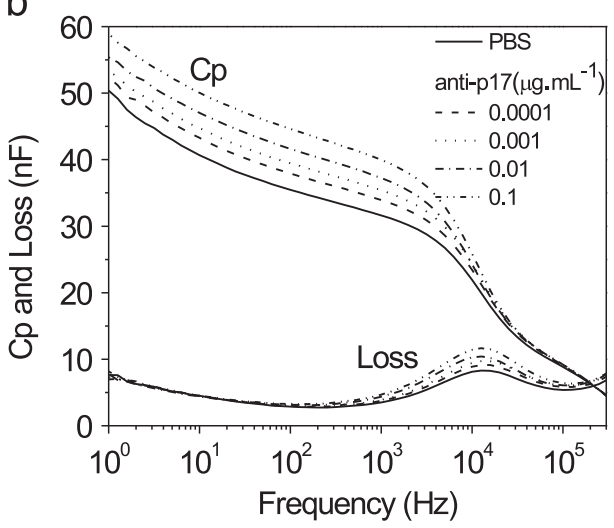

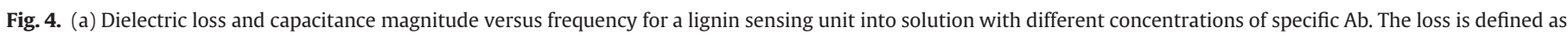

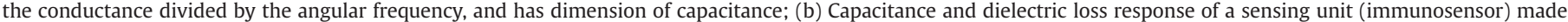

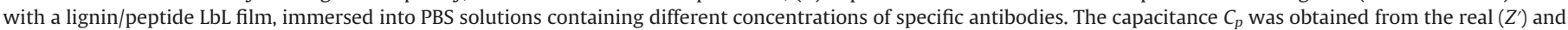
imaginary $\left(Z^{\prime \prime}\right)$ parts of the impedance as $C_{p}=-Z^{\prime \prime} \mid\left[\omega\left(Z^{\prime \prime 2}+Z^{\prime 2}\right)\right]$.

in multidimensional projections are aimed at preserving the similarity of data instances (i.e. samples) in the original data space when they are projected onto the 2-dimentional plot. Further details about the IDMAP technique can be found in (Paulovich et al., 2007; Ha et al., 2008; Worch et al., 2012).

\section{Results and discussion}

\subsection{Layer-by-layer films of lignin and lignin/peptide}

Lignin is capable of forming H-bonding, which allowed us to produce multilayer films with neat lignin. That is to say, lignin layers were adsorbed on top of previously grown layers and $\mathrm{LbL}$ films with 5 or 6 layers could be built, as shown in Fig. 2. Obviously, adsorption in this case is not driven by electrostatic attraction since the molecules were all negatively charged, with a zeta potential of $-20.4 \mathrm{mV}$ for lignin solution. The absorbance spectra for 6-layer LbL films of lignin and lignin/peptide, shown in Fig. 3a, display a band centered at $280 \mathrm{~nm}$, assigned to the $\pi-\pi *$ electronic transition from phenyl groups of the lignin. For lignin films its intensity increased linearly with the number of immersion steps as indicated in Fig. 3b. The linear increase allows one to conclude that a similar amount of lignin is deposited in each layer (Volpati et al., 2011; Alessio et al., 2008; Gomes et al., 2013) which is surprising for a film with predominating secondary interactions (see below). For the lignin/peptide film, growth in Fig. 3b appears to be exponential as in many LbL films made with biomolecules (Gomes et al., 2013; Lavalle et al., 2002), which is probably due to the presence of secondary H-bonding interactions.

The observed behavior is consistent with two regimes most found for growth in LbL films which are the linear and exponential regimes (Gomes et al., 2013; Lavalle et al., 2002). For films with highly charged polyelectrolytes, adsorption may be driven by electrostatic attraction and a linear increase in mass or thickness is observed (Boudou et al., 2010). When there are secondary interactions such as H-bonding film growth may be exponential. To establish a priori which type of growth will be observed for a given system is not straightforward because several parameters may affect the growth mechanisms. For instance, Lavalle et al. (2002) reported changes from linear to exponential growth for some systems merely by altering ionic strength and/or temperature. We mentioned above that the linear growth for the LbL films containing only lignin was surprising because to our knowledge there
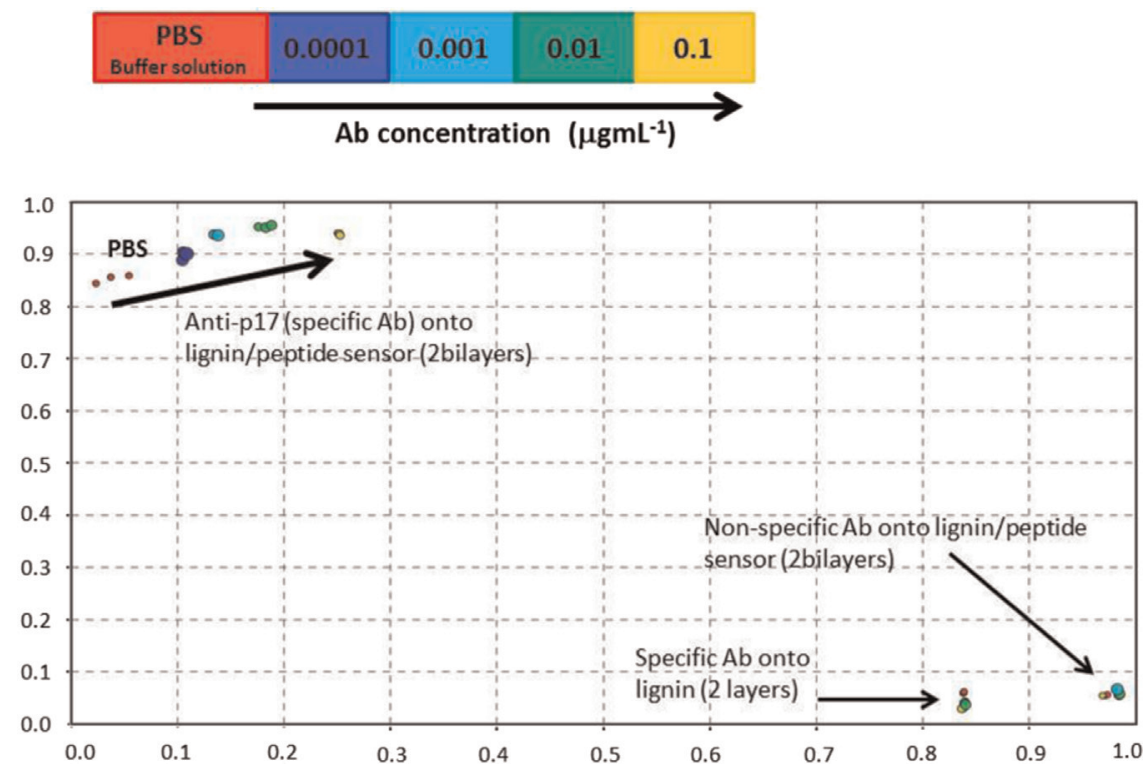

Fig. 5. Visualization of the electric impedance curves using the Multidimensional Projection Technique IDMAP. 
Table 1

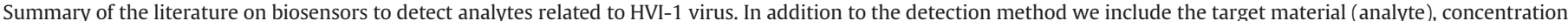
range and detection limit.

\begin{tabular}{|c|c|c|c|c|}
\hline Detection method & Target material & Concentration range & Detection limit & Reference \\
\hline $\mathrm{QCM}^{*}$ & gp 41 & $5-200 \mathrm{ng} / \mathrm{ml}$ & $2 \mathrm{ng} / \mathrm{mL}$ & Lu et al. (2012) \\
\hline Fluorescent & $\mathrm{p}-24$ & $4-20 \mathrm{ng} / \mathrm{mL}$ & - & Biancotto et al. (2009) \\
\hline Amperometric & $\mathrm{p}-24$ & $0.01-60 \mathrm{ng} / \mathrm{mL}$ & $0.0064 \mathrm{ng} / \mathrm{mL}$ & Kheiri et al. (2011) \\
\hline $\mathrm{DPV}^{*}$ & $\mathrm{p}-24$ & $0.001-10 \mathrm{ng} / \mathrm{mL}$ & $0.5 \mathrm{pg} / \mathrm{mL}$ & Gan et al. (2013) \\
\hline $\mathrm{CV}^{*}$ & HIV -1 VLP & $0.6-375 \mathrm{pg} / \mathrm{mL}$ & - & Lee et al. (2013) \\
\hline EIS $^{*}$ & $\mathrm{p}-17$ & $0.1-100 \mathrm{ng} / \mathrm{mL}$ & - & Present work \\
\hline
\end{tabular}

* QCM: Quartz Crystal Microbalance, DPV: Differencial Pulse Voltammetry, CV: Cyclic Voltammetry, EIS: Electrical Impedance Spectroscopy.

has been no report of such behavior for growth governed by H-bonding. Nanostructured lignin films have indeed been produced with the Langmuir-Blodgett (LB) technique (Pasquini et al., 2005; Pereira et al., 2007), but the mechanisms for growth should be different from those in LbL films. With the data reported here, we cannot identify the reasons for the differences in film growth, since this might only be achieved if a systematic study on adsorption of lignin films, under varied experimental conditions, is performed, which is outside the scope of the present article. For the lignin/peptide LbL film, growth is exponential according to Fig. $3 a$, then indicating that $\mathrm{H}$-bonding in addition to electrostatic interactions should occur. The importance of electrostatic interactions is inferred from the negative zeta potential for the lignin solution $(-20.4 \mathrm{mV})$ and positive potential for the peptide at $\mathrm{pH}$ 5.0 , whose isoelectric point is 8.74 . H-bonding should be expected from the lignin structure as discussed in connection with Fig. 1.

This surface characterization of the LbL films is complemented with an AFM analysis, whose images are discussed in Section 3.3.

\subsection{Immunosensing with electrical measurements}

Fig. 4a shows that the electrical properties of a sensing unit containing only lignin (therefore it is not an immunosensor) are almost unaffected by adding specific antibodies to the PBS solution. Indeed, the dielectric loss peak and the capacitance, which correspond to the real and imaginary parts of the admittance, respectively, did not change significantly in the presence of specific Ab. For instance, the capacitance at $10 \mathrm{~Hz}$ for PBS is $181 \mathrm{nF}$ while for $0.1 \mu \mathrm{g} \mathrm{mL}^{-1}$ of specific Ab it is $180 \mathrm{nF}$. As one should expect the electrical properties were not modified significantly if there are no specific interactions between lignin and the Ab.

In contrast, the electrical response changed strongly for the sensing unit (immunosensor) containing the peptide (Fig. 4b), where both capacitance and maximum of dielectric loss curves depended on the specific $\mathrm{Ab}$ concentration. Upon increasing the $\mathrm{Ab}$ concentration the capacitance increased significantly at frequencies lower than $5 \mathrm{kHz}$. At $10 \mathrm{~Hz}$, for example, capacitance increased from $40.6 \mathrm{nF}$ for PBS to $50.0 \mathrm{nF}$ as the concentration of Ab solution increased from 0.0 to $0.1 \mu \mathrm{g} \mathrm{mL}^{-1}$. The dielectric loss peak $(1 / \mathrm{R})$ at $\approx 14 \mathrm{kHz}$ also increased. Such behavior is typical of increased film conductance with increasing electrolyte concentration, providing further evidence of adsorption of charged species onto the sensing unit (Taylor and Macdonald, 1987). In the present case, it could be argued that the change in the electrical properties of the lignin/peptide sensing unit arises from adsorption of the specific $\mathrm{Ab}$ onto the sensor, which was actually confirmed with AFM measurements to be mentioned later on. For concentrations above $0.1 \mu \mathrm{g} \mathrm{mL}^{-1}$ the changes in the electrical response became increasingly small owing to saturation of adsorption sites. In Fig. S1 in the Supporting Information we show the original plots for the modulus of the impedance versus frequency for the data in Fig. 4b. The high sensitivity is illustrated by plotting the capacitance at $100 \mathrm{~Hz}$ versus concentration in Fig. S2, where the capacitance is seen to vary exponentially with the concentration, as in a Langmuir adsorption isotherm (Langmuir, 1918).

One of the most important features of an immunosensor is specificity. In addition to verifying that incorporation of specific antibodies affected the electrical response of the lignin/peptide immunosensor but not of a lignin sensing unit, we measured the impedance for the immunosensor in the presence of anti-HCV antibodies, which are specific for Hepatitis $C$ disease. In this control experiment, the dielectric loss and the capacitance curves almost coincided with the curves for the PBS solution and therefore the curves are omitted. This indicates the lack of specific interaction between the peptide and the non-specific (anti-HCV) antibodies. When this same electrode coated with the lignin/peptide LbL film was exposed to a specific Ab solution, large changes in capacitance and loss curves were observed, as in the experiments discussed in Fig. 4b.

To confirm the distinguishing ability of immunosensors is a difficult challenge when data are collected from a large number of samples. If impedance spectroscopy is used as the principle of detection, measurements with many samples will lead to many curves, whose proper visualization may require special methods. Here we employed a multidimensional projection technique, referred to as Interactive Document Map IDMAP (Moraes et al., 2010), to display each curve from the impedance spectra into a single point in the 2-Dimensional project space. With IDMAP all spectra similar in the original space are placed close in the a

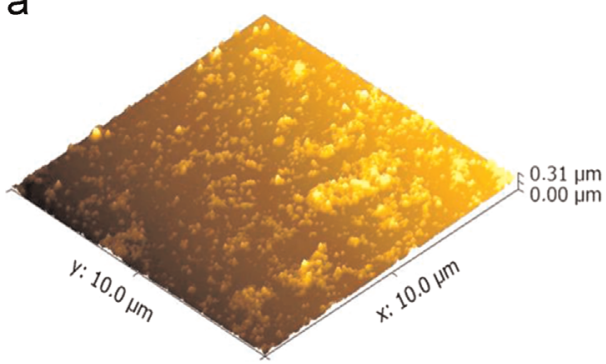

b

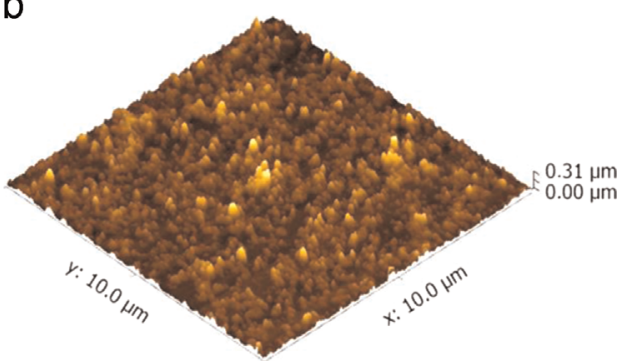

Fig. 6. AFM images of the lignin/peptide sensing unit before (a) and after exposure to $\left(0.1 \mu \mathrm{L} \mathrm{mL}^{-1}\right)$ specific $A b$ solution (b). 
projected space. In other words, two similar capacitance curves will be represented by two points placed close to each other on the 2D plot. Fig. 5 shows that the data points for the lignin unit sensor with no peptide are clustered together and the same applies to the data obtained with the non-specific Ab (anti-HCV). On the other hand, very good distinction was obtained with the samples of the specific Ab (anti-p17) measured with the immunosensor containing the p17 peptide. This is shown in the left hand side in Fig. 5, thus representing a confirmation of the immunosensor selectivity.

The lowest concentration of specific Ab used in our experiments, $0.0001 \mu \mathrm{g} \mathrm{mL}^{-1}$, is comparable to the detection limit of most biosensors based on electrical or electrochemical such as amperometric, and electrochemical immunosensors for determination of alpha-feto protein in human serum (Giannetto et al., 2011), and for detection of HIV1 and HIV2 (Gan et al., 2013; Biancotto et al., 2009; Kheiri et al., 2011; Wang et al., 2007), and immunosensors for detecting the avian influenza virus, whose signal was maximized in impedance measurements (Wang et al., 2007). This lowest concentration is still higher than the limit of detection of fluorescence-based immunosensors (Zheng et al., 2012; Gan et al., 2013; Moraes et al., 2013; Biancotto et al., 2009; Kheiri et al., 2011; Wang et al., 2007; Lee et al., 2013) or biosensors with optimized, more complex architectures (Gan et al., 2013; Bhimji et al., 2013; Kheiri et al., 2011). A direct comparison with the results published in the literature is shown in Table 1 . The performance of our immunosensor based on impedance spectroscopy can obviously be optimized by testing other architectures or even using other statistical approaches to treat the data, but our interest here has been to demonstrate that low-cost, easy-to-use immunosensors can be an important alternative for point-of-care diagnosis.

We also tested the lifetime of the immunosensor, by performing experiments where detection of the specific $A b$ was realized with sensing units stored in a PBS solution and under ambient environment in a refrigerator at $8-6{ }^{\circ} \mathrm{C}$ for up to 60 days. The immunosensors prepared $1,3,5,10,20,30,40,50$ and 60 days before the actual measurement with the specific Ab-containing PBS solutions all led to significantly different electrical responses for three concentrations, in comparison to pure PBS. By way of illustration we show in Figs. S3 and S4 in the Supporting Information the data for an immunosensor used 60 days after its fabrication. These results confirm the preservation of the p17 activity, which is superior to many enzyme-based immunosensors, whose lifetime is normally limited to $4-6$ weeks.

\subsection{Investigating the mechanism of detection with AFM}

With regard to sensing and biosensing, atomic force microscopy (AFM) has mostly been used to characterize sensing units (Moraes et al., 2010; Volpati et al., 2011; Gomes et al., 2013), but there are cases in which surface probe microscopies are employed as part of the sensing itself. This is especially true with atomic force spectroscopy measurements where force curves can assist in confirming the selectivity of biosensors (Steffens et al., 2014) and even relate the nanomechanical properties of bacteria detected with electrochemical impedance spectroscopy (Liu et al., 2013). We used AFM to verify whether the morphology of the sensing unit was affected by the detection measurements, particularly because in immunosensing one does expect strong adsorption of the analyte. We noted considerable changes in film morphology when the specific Ab was made to interact with the sensor containing the peptide p17-1, which is attributed to adsorption. Fig. 6 shows AFM images revealing a marked difference between a neat lignin/peptide unit sensor and one such film exposed to specific $\mathrm{Ab}$. After adsorption of the Ab, film surface was densely populated, with the film roughness increasing to $18.4 \mathrm{~nm}$, to be compared with $9.5 \mathrm{~nm}$ for the neat lignin/peptide film. In contrast, no significant change in morphology and roughness was observed after exposing sensing units to non-specific Ab, confirming the expected absence of adsorption (images not shown). Such changes in morphology are consistent with the literature (Moraes et al., 2010; Alessio et al., 2008; Gomes et al., 2013; Steffens et al., 2014).

\section{Conclusion and perspectives}

We were successful in the preparation of a selective immunosensor for HIV whose high sensitivity arises from adsorption of the anti-p17 (specific Ab), for which lignin was proven suitable as immobilization matrix. The architecture for optimized performance was a simple 2-bilayer LbL film deposited onto interdigitated gold electrodes. The selectivity of the immunosensor made with lignin/peptide bilayers was demonstrated with impedance spectroscopy measurements and atomic force microscopy images in two types of control experiments. In the first, the electrical response of a sensing unit containing lignin only was not affected when it was exposed to PBS solutions containing the specific $\mathrm{Ab}$. In the second type of control experiment, we demonstrated that the electrical response and surface morphology of the immunosensor containing the lignin/peptide LbL film were not affected by exposure to PBS solutions of a non-specific Ab (anti$\mathrm{HCV}$ ). Here we employed only one type of lignin, but one may predict that lignins obtained from other sources and/or via other experimental extraction procedures should also amenable to function as matrix for the LbL films. This statement is based on the fact that lignin is used as matrix, with no active role in the detection mechanisms, and on the literature (Balogh et al., 1992; Vallejos et al., 2011), according to which the overall lignin properties in terms of the functional groups do not vary significantly by changing the type of lignin. In summary, we demonstrated the feasibility of producing immunosensors with the LbL deposition method, using neat lignin as immobilization matrix, again supporting the valorization of this abundant, inexpensive agricultural byproduct. Most importantly, the immunosensors produced point to the possibility of obtaining all-organic, biocompatible devices.

The strong, irreversible adsorption of the specific $\mathrm{Ab}$ onto the LbL film used for immunosensing means that the sensing units cannot be reused. This is not actually a limitation since one does not expect to reuse the sensing units in clinical diagnostics. Another advantage of the immunosensors made with peptide $\mathrm{p}-17$ is the lifetime of 60 days at the least, which is superior to the usual one for enzyme-based biosensors. Though the performance of the immunosensor based on impedance spectroscopy could still be optimized, the lowest concentrations detected are already sufficient for blood tests in real settings, since the sensitivity is comparable to results reported with the ELISA method (Kheiri et al., 2011; Lee et al., 2013).

\section{Acknowledgments}

This work was supported by FAPESP, CNPq and CAPES (Brazil). We thank the microfabrication laboratory (LMF/LNNano) (Brazil) for providing interdigitated electrodes (Project LMF 12298). We also thank M.H.O. Piazzetta (LNNANO-Microfabrication Laboratory, Campinas, SP-Brazil) and Dr. Débora T. Balogh (IFSC-USP, São Carlos, SP Brazil).

\section{Appendix A. Supplementary material}

Supplementary data associated with this article can be found in the online version at http://dx.doi.org/10.1016/j.bios.2015.04.054. 


\section{References}

Alessio, P., Cavalheri, A.S., Pasquini, D., Curvelo, A.A.S., Constantino, C.J.L., 2008 Fabricação de filmes ultrafinos de lignina de bagaço de cana-de-açucar via evaporação térmica a vácuo. Rev. Bras. Apl. Vácuo 27, 169-174.

Aoki, P.H.B., Alessio, P., Furini, L.N., Constantino, C.J.L., Neves, T.T.A.T., Paulovich, F.V., de Oliveira, M.C.F., Oliveira Jr., O.N., 2013. Molecularly designed layer-by-layer (LbL) films to detect catechol using information visualization methods. Langmuir 29, 7542-7550.

Balogh, D.T., Curvelo, A.A.S., De Groote, R.A.M.C., 1992. Solvent effects on organosolv lignin from pinus caribea hondurensis. Holzforschung 46, 343-348.

Biancotto, A., Brichacek, B., Chen, S.S., Fitzgerald, W., Lisco, A., Vanpouille, C., Margolis, L., Grivel, J.C., 2009. A highly sensitive and dynamic immunofluorescent cytometric bead assay for the detection of HIV-1 p24. J. Virol. Methods 157, 98-101.

Bhimji, A., Zaragoza, A.A., Live, L.S., Kelley, S.O., 2013. Electrochemical enzymelinked immunosorbent assay featuring proximal reagent generation: detection of human immunodeficiency virus antibodies in clinical samples. Anal. Chem. 85, 6813-6819.

Boudou, T., Crouzier, T., Ren, K., Blin, G., Picart, C., 2010. Multiple functionalities of polyelectrolyte multilayer films: new biomedical applications. Adv. Mater. 22, 441-467.

Cerrutti, B.M., de Souza, C.S., Castellan, A., Ruggiero, R., Frollini, E., 2012. Carboxymethyl lignin as stabilizing agent in aqueous ceramic suspensions. Ind. Crops Prod. 36, 108-115.

Dhand, C., Das, M., Datta, M., Malhotra, B.D., 2011. Recent advances in polyaniline based biosensors. Biosens. Bioelectron. 26, 2811-2821.

Ferreira, Q., Gomes, P.J., Ribeiro, P.A., Jones, N.C., Hoffmann, S.V., Mason, N.J., Oliveira Jr., O.N., Raposo, M., 2013. Determination of degree of ionization of poly(allylamine hydrochloride) (PAH) and Poly[1-[4-(3-carboxy-4 hydroxyphenylazo) benzene sulfonamidol-1,2-ethanediyl, sodium salt] (PAZO) in layer-by-layer films using vacuum photoabsorption spectroscopy. Langmuir 29, 448-455.

Gan, N., Du, X., Cao, Y., Hu, F., Li, T., Jiang, Q., 2013. An ultrasensitive electrochemical immunosensor for HIV p24 based on $\mathrm{Fe}_{3} \mathrm{O}_{4} @ \mathrm{SiO}_{2}$ nanomagnetic probes and nanogold colloid-labeled enzyme-Ab copolymer as signal tag. Materials 6, 1255-1269.

Gasparotto, L.H.S., Castelhano, A.L.B., Gabriel, R.C., Dantas, N.O., Oliveira Jr., O.N., Siqueira Jr., J.R., 2013. Electrogeneration of platinum nanoparticles in a matrix of dendrimer-carbon nanotubes. Phys. Chem. Chem. Phys. 15, 17887-17892.

Giannetto, M., Mori, L., Mori, G., Careri, M., Mangia, A., 2011. New amperometric immunosensor with response enhanced by PAMAM-dendrimers linked via self assembled monolayers for determination of alpha-fetoprotein in human serum. Sens. Actuators B Chem. 159, 185-192.

Gomes, M.N., Brito, J.B., Silva, J.R., de Souza, N.C., 2013. Layer-by-Layer films from wine: an investigation of an exponential growth process. J. Nanomater., 1-7.

Hirotsu, K., Goto, M., Okamoto, A., Miyahara, I., 2005. Dual substrate recognition of aminotransferases. Chem. Rec. 5, 160-172.

Karlsson, A.M., Bjuhr, K., Testorf, M., Oberg, P.A., Lerner, E., Lundstrom, I., Svensson, S.P., 2002. Biosensing of opioids using frog melanophores. Biosens. Bioelectron. $17,331-335$.

Kheiri, F., Sabzi, R.E., Jannatdoust, E., Shojaeefar, E., Sedghi, H., 2011. A novel amperometric immunosensor based on acetone-extracted propolis for the detection of the HIV-1 p24 antigen. Biosens. Bioelectron. 26, 4457-4463.

Langmuir, I., 1918. The adsorption of gases on plane surfaces of glass, mica and platinum. J. Am. Chem. Soc. 40, 1361-1403.

Lavalle, P.H., Gergely, C., Cuisinier, F.J.G., Decher, G., Schaaf, P., Voegel, C., Picart, J.C., 2002. Comparison of the structure of polyelectrolyte multilayer films exhibiting a linear and an exponential growth Regime: an in situ atomic force microscopy study. Macromolecules 35, 4458-4465.

Lee, Jin-Ho, Byeung-Keun., Oh, Choi, Jeong-Woo, 2013. Electrochemical sensor based on direct electron transfer of HIV-1 Virus at Au nanoparticle modified ITO electrode. Biosens. Bioelectron. 49, 531-535.

Liu, B.H., Li, K.L., Kang, K.L., Huang, W.K., Liao, J.D., 2013. In situ biosensing of the nanomechanical property and electrochemical spectroscopy of Streptococcus mutans-containing biofilms. J. Phys. Appl. Phys. 46, 275401.

Lu, L., Liu, B., Zhao, Z., Ma, C., Luo, P., Liu, C., Xie, G., 2012. Ultrasensitive electrochemical immunosensor for HE4 based on rolling circle amplification. Biosens. Bioelectron. 33, 216-221.

Luo, R., Zhang, W., Cheng, W., Zhao, D., Li, Y., Lin, X., Fang, D., Ding, S., 2013. A novel electrochemical immunosensor for detection of angiotensinII at a glass carbon electrode modified by carbon nanotubes/chitosan film. Int. J. Electrochem. Sci. 8, 3186-3196.

Makaraviciute, A., Ramanaviciene, A., 2013. Site-directed antibody immobilization techniques for immunosensors. Biosens. Bioelectron. 50, 460-471.
Minghim, R., Paulovich, F.V., Lopes, A.A., 2006. Content-based text mapping using multi-dimensional projections for exploration of document collections SPIEIS\&T. 6060 60600S-11.

Mishra, S.K., Kumar, D., Rajesh, Biradar, A.M., 2012. Electrochemical impedance spectroscopy characterization of mercaptopropionic acid capped ZnS nanocrystal based bioelectrode for the detection of the cardiac biomarker-myoglobin. Bioelectrochemistry 88, 118-126.

Moraes, M.L., Maki, R.M., Paulovich, F.V., Rodrigues Filho, U.P., de Oliveira, M.C.F., Riul, A., de Souza, N.C., Ferreira, M., Gomes, H.L., Oliveira Jr., O.N., 2010. Strategies to optimize biosensors based on impedance spectroscopy to detect phytic acid using layer-by-layer films. Anal. Chem. 82, 3239-3246.

Moraes, M.L., Lima, L.R., Silva, R.R., Cavicchioli, M., Ribeiro, S.J.L., 2013. Immunosensor based on immobilization of antigenic peptide NS5A-1 from HCV and silk fibroin in nanostructured films. Langmuir 29, 3829-3834.

Oliveira Jr., O.N., Pavinatto, F.J., Constantino, C.J.L., Paulovich, F.V., de Oliveira, M.C.F. 2012. Information visualization to enhance sensitivity and selectivity in biosensing. Biointerphases 53, 1-4.

Oliverio, J., Hilst, A., 2004. DHR-DEDINI Hidrólise Rápida (DEDINI Rapid Hydrolysis)-revolutionary process for producing alcohol from sugar cane bagasse. Int. Sugar J. 106, 168-172.

Pasquini, D., Balogh, D.T., Oliveira Jr., O.N., Curvelo, A.A.S., 2005. Lignin molecular arrangements in Langmuir and Langmuir-Blodgett films: the influence of extraction processes. Colloids Surf. A: Physicochem. Eng. Aspects 252, 193-200.

Paulovich, F.V., Moraes, M.L., Maki, R.M., Ferreira, M., Oliveira Jr, O.N., de Oliveira, M C.F., 2011. Information visualization techniques for sensing and biosensing. Analyst 136, 1344-1350.

Paulovich, F.V., de Oliveira, M.C.F., Minghim, R., 2007. In: Proceedings of the Brazilian Symposium on Computer Graphics and Image Processing, 21, pp. 27-34

Pereira, A.A., Martins, G.F., Antunes, P.A., Conrado, R., Pasquini, D., Job, A.E., Curvelo A.A.S., Ferreira, M., Riul Jr., A., Constantino, C.J.L., 2007. Lignin from sugar cane bagasse: extraction, fabrication of nanostructured films, and applications. Langmuir 23, 6652-6659.

Ha, S., Seo, Young-Ju, Kwon, Min-Seok, Chang, Byung-Ha, Han, Cheol-Kyu, Yoon, Jeong-Hyeok, 2008. IDMap: facilitating the detection of potential leads with therapeutic targets. Bioinformatics 24, 1413-1415.

Sacanna, S., Irvine, W.T.M., Chaikin, P.M., Pine, D.J., 2010. Lock and key colloids. Nature 464, 575-578.

Siqueira Jr, J.R., Maki, R.M., Paulovich, F.V., Werner, C.F., Poghossian, A., de Oliveira, M.C., Zucolotto, V., Oliveira Jr, N., Schöning, M.J., 2010. Use of information visualization methods eliminating cross talk in multiple sensing units investigated for a light-addressable potentiometric sensor. Anal Chem. 82, 61-65.

Sombatsri, S., Wittayakun, J., Sanai, K., Kajsanthia, K., Prayoonpokarach, S., 2012. An optical sensing film for the determination of $\mathrm{Co}(\mathrm{II})$ based on disodium-1-nitroso-2-naphthol-3,6-disulfonate immobilized in chitosan film. Sens. Actuators B Chem. 166-167, 772-776.

Steffens, F.L.L., Manzoli, A., Sandoval, R.D., Fatibello, O., Herrmann, P.S.P., 2014. Microcantilever sensors coated with doped polyaniline for the detection of water vapor. Scanning 36, 311-316.

Taylor, D.M., Macdonald, A.G., 1987. AC admittance of the metal/insulator/electrolyte interface. J. Phys. Appl. Phys. 20, 1277-1283.

Vallejos, M.E., Felissia, F.E., Curvelo, A.A.S., Zambon, M.D., Ramos, L., Area, M.C., 2011. Chemical and physico-chemical characterization of lignins obtained from etanol-water fractionation of bagasse. Bioresources 6, 1158-1171.

Vieira, N.C.S., Figueiredo, A., Faceto, A.D., de Queiroz, A.A.A., Zucolotto, V., Guimarães, F.E.G., 2012. Dendrimers $/ \mathrm{TiO}_{2}$ nanoparticles layer-by-layer films as extended gate FET for pH detection. Sens. Actuators B Chem. 169, 397-400.

Volpati, D., Machado, A.D., Olivati, C.A., Alves, N., Curvelo, A.A.S., Pasquini, D., Constantino, C.J.L., 2011. Physical vapor deposited thin films of lignins extracted from sugar cane bagasse: morphology, electrical properties, and sensing applications. Biomacromolecules 12, 3223-3231.

Wang, Y., Ronghui, W., Yanbin, L., 2007. In: Proceedings of the ASAE Annual Meeting, Minneapolis, Minnesota, pp. 2-12.

Worch, T., Lê, S., Punter, P., Pagès, J., 2012. Construction of an Ideal Map (IdMap) based on the ideal profiles obtained directly from consumers. Food Quality Prefer. 26, 93-104.

Yin, H., Ai, S., Shi, W., Zhu, L., 2009. A novel hydrogen peroxide biosensor based on horseradish peroxidase immobilized on gold nanoparticles-silk fibroin modified glassy carbon electrode and direct electrochemistry of horseradish peroxidase. Sens. Actuators B Chem. 137, 747-753.

Zheng, L., Jia, L., Li, B., Situ, B., Liu, Q., Wang, Q., Gan, N., 2012. A sandwich HIV p24 amperometric immunosensor based on a direct gold electroplating-modified electrode. Molecules 17, 5988-6000. 